11th International Vacuum Congress (IVC-11)/7th International Conference on Solid Surfaces (ICSS-7), Cologne, FRG, 7/25-29/89.

\section{METAL AND ELASTOMER SEAL TESTS FOR ACCELERATOR APPLICATIONS}

K.M. Welch, G.T. Mclatyre, J.E. Tucooolo, R. Skelton, DJ. Pate, S.M. Gill
BNL --43100

DE89 017607

ver 141989

\begin{abstract}
The vacuum system of the Alternating Gradient Synchrotron (AGS) at Broothaven National Laboratory has more than a thonsand metal vecuum sealk. Also, numerous elastomer seals are used throughort the AGS to seal large beam component chambers. An accelerator upgrade program is being implemented to reduce the AGS operating pressure by 700 and improve the reliabiity of the yacuum system. This paper describes wort in progress on metal and elastomer vacuum seals to help meet these two objectives. Teats are reported on the sealing properties of a variety of metal seals nsed on different sealing surfaces. Results are also given on reversible sorption properties of certain elastomers.
\end{abstract}

\title{
INTRODUCTION
}

The racuum system of the Alternating Gradient Synchrotron (AGS) at Brookhaven National Laboratory has more than a thoueand metal vacuum seak. Also, elastomers are used to seal numerous hroe bean component chambers such as ion profile monitors, wire and magactic septa, twne meters and chambers containing ferrite magnets. An accelerator aparade program is being implemented to reduce the AGS operating presenre by $x 100$ and improve the reliability of the vacuum system Elimination of the elastomers and use of more reliable metal seals is required to meet these objectives.

Two years ago, most of the metal vacuum seals used thronghon the AGS were Indium costed, Incone? X750 C-rings. These metal seals proved to be unrelinble for reasons including spontaneous cracking of the Inoced C-ring and poor shelf life. The cracking phenomenon, usually completely severing a minor diameter, might happen while stored in the shipping container. In instances it has occurred to C-rings installed in the AOS, wh catratrophic consequences. Inconel C-rings are usually age-hordened for added strength. They are then In coated. It is believed that this conting process results in hydrogen embrittlement which, in turn, causes the spontameons crecking.

\footnotetext{
"Work performed under the auspices of the US. Depertmeat of Energy.
}

\section{DISCLAIMER}

\footnotetext{
This report was prepared as an account of work sponsored by an agency of the United States Government. Neither the United States Government not any agency thereof, nor any of their employees, makes any warranty, express or implied, or assumes any legal liability or responsibility for the accuracy, completeness, or usefulness of any information, apparatus, product, or process disclosed, or represents that its use would not infringe privately owned rights. Reference herein to any specific commercial product, process, or service by trade name, trademark, manufacturer, or otherwise does not necessarily constitute or imply its endorsement, recommendation, or favoring by the United States Government or any agency thereof. The views and opinions of authors expressed herein do not necessarily state or reflect those of the
} United States Government or any agency thereof. 
The second problem is the deleterious oxidation of the In coating; this shelf-life problem can occur after storage for a year or more. It has not been verified that installed seals have problems because of this oxide formation. However, installed seals, which were once vacuum tight, from time to time inexplicably develop lestes.

Seals with this oxide layer, probably InO, will leak even under ideal test conditions. Becaue of this problem, tecturicians developed the procedure of toroidally wrapping all new and reused C-rings with three layers of In foil. This ws labor intencive and camed virnal leaks on installation; however, it was the onty means whereby relisble vecuum senls could be achieved.

The spontaneous cracking problean bus been 'solved' on several occasions by better process control. But, the readors tend to forget the recipe. The problem of InO formation could be solved by better packsing or even storage under vacuum. However, these problems prompted us to seek alternative seal configurations.

A seal teat program was initiated to identify more switable metal seals. It was also boped this work woukd also lead to the ideatification of metal replacement seals for the many large-diameter elastomer seals used in the AGS. Neglecting reliability problems deve to radiation effects on elastomers and beam loss considerations, the presence of elastomers within the AGS results in the loss of experimental beam time. For example, accelerator sector pumpdown times are often extended by $x 2$ due to the reversible gas sorption mechanismos of these elastomers. To both educate and motivate the staff, verification tests were conducted on outgassing rates of elastomers. These data were augmented with the results of elastomer weight-loss studies conducted at the Stanford Linear Accelerator Center (SLAC) several years ago. These results are also given.

\section{SEALING BOUNDARY CONDITIONS}

The seal boundary conditions were eetablished by the presen hardware in the AGS. Seals had to be suitable for use in eristing bolted flanges with O-ring type grooves. Also, they had to be suitable for seating Marmon-type flanges, ranging from $180-330 \mathrm{~mm} \phi$, and secured with four-segment, Al clamps. In this latter application, seals are mounted between the fingses with a removable retainer, rather than being retained in O-ring groovec. Seals had to be capable of sealing againat flat stainless steel, aluminum and porcelain enamel coated surfaces, all having nominal surface finishes of $=1.0 \mathrm{\mu m}$. Some of the existing flanes have scratched surfaces. Over 500 enamel coated flanges are used in the ACS. These conted finnges are used to eloctrically isolate flange pair. The sealing force for claroped, Anore pairs was set at $\leq 1400 \mathrm{~N} / \mathrm{cm}$; this was set by the design of new champe to be installed with the successful seal candidate. "Tapping" of clamps to achiere uniform sealing was prohibited, as 
the distinction between "tapping" and "pounding" is subjective. Prior to installing clamps, they are first sprayed with a dry lubricant.

Criteria weighed whea selecting vacumm seal designs include the following safety; reliability, bakeability, seal permeation rate; materiai outgassing sates; mating surface materials; mating surface finish; ease of installation (e.g) technique involved); required sealing force; applicable flange sizes; provision for cleaning of parts; initial costs; operating costs (i.e., replacement and reusability); seal avilability for replacement; degree of radiation "hardness"; handling fragility, and shelf iffe.

\section{METAL SEALS}

Varieties of all-metal seals inchude the: Coaflat-type (i.e, knife-edge, coined gaskets, or stepped);[1] Wheeler' (special wire seal); [2] Foil (Al, In, Cu); [3] Wire (Al, Al, A\& $\mathrm{Cu}$, In, etc); [3] C-ringa, conted with soft metals such as In or $\mathrm{Pb}$, and which may or may not be reiaforced with a spring; $C$-rings of Inconel, jecketed with a ductal metal such as $A C, C u$ and spring reinforced; $[4] \mathrm{C}$-ringe, with "diamond" edges, and spring reinforced (i.e., the Helicoflex Delta' Seal; Fig 1) [5] and "diamond" seals (Fig. 2). [5]

Whecler sufficiently characterized the first two varieties of seals for them to be dismissed as viable candidales, for reasons already noted. [1,2] Also, installing large diameter ConFlat and Wheeler seals is time-consuming. To minimize exposure of personnel to residual radiation in the AGS, extensive use of these seals is avoided. The third and forth varieties of seals listed above were dismissed for sealing force, reliability, cost or safety reasons. Varieties of the remaining candidates were tested.

\section{METAL SEAL TESTS AND RESULTS}

Tests consisted of squeezing the seal between a 300 series stainless steel mandreh, and sealing plates of either aluminum, stainless steel or enamel coated stainless steel. The mandrel was positioned in a precision bydraulic ram. The joints were leak checked by pumping between the two plates through a hole in the bortom of the mandrel. Any indication of a leak constituted a seal failure. Teat seals had major diameters of $\approx 150 \mathrm{~mm}$, with minor dimensions of $\approx 5.0 \mathrm{~mm} \phi$, excepting the "diamond" seal. A leak detector with an MDS of $\leq 2 \times 10^{-10}$ Torr- $L / \mathrm{sec} H \mathrm{He}$ was used. A seal test was arbitrarily terminated if seal deflection exceeded $=1.0 \mathrm{~mm}$ during loading, or seal loading exceeded $\approx 1850 \mathrm{~N} / \mathrm{cm}$.

Results of these tests are given in Tables I-III. All data are reported. The numbers listed vertically in each column of the tables represent the sequence of cycle-loading of one seal. Load-strain data for each type of seal were recorded and are given in Fig. 3. Each time a successful seal was achieved, 
seal deflection was measured. Then, the bydraulic ram was "released", and the seal height again measured. The plates were not parted between measurements. That is, the indexing berween the sealing plates and seal was not changed betweea each measurement. Because of this, one may not interpret the existence of successive data in any one coluoun as indicating that the seal is reusable. However, the absence of a consecutive number in any one column implies that the seal would not reseal on the next application of pressure, within the prescribed limits.

Results with the In conted C-rings was very poor. The plastic bags within which these had been stored were aot adequately sealed. There was visible oxidation and "finger prints" on some the surfaces. Freshly costed In C-riogs probably would have yielded better results (e.g, 350 - $700 \mathrm{~N} / \mathrm{cm}$ sealing force). However, test results merely emphasize the serious shelf-life problem.

The diamond seal and the $\mathbf{P b}$ costed, spring reinforced $\mathrm{C}$-rings proved promising when sealing against metal surfaces. However, results were poor when sealing against enamel coated surfaces. It is possible that changing the included angle of the diamond sealing edge might have improved the performance of this seal. However, the temptation of "drifting" into a seal development program was avoided. Data on the Pb coated, spring reinforced C-rings should prove useful in calculating probable $C$-ring stress, as a function of required seal loading, for applications of unreinforced $P b$ coated $C$-rings.

Results with the $A$ lacketed, spring reinforced $C$-rings were not at all promising. Disparities in our data from that reported in the literature[4] probably stem from differences in surface finishes and our use of a lower seal loading test limit. [6]

The Helicoflex Delta' seal ("Delta", hereafter) appeared the most promising. Only two Cu jacketed Delta seals were tested (i.e., Table I). The remaining had $A \ell$ jackets. Tests were subsequently conducted to determine if the Delta seals couid be reused. A magnet chamber, with a $240 \mathrm{~mm} \phi$, stainless steel Marmon flange on one end and enamel coated flange on the other, was used for this purpose. A Delta seal and blank Al flange was installed on one end of the chamber. A like seal and stainless steel flange with pumpout was jnstalled on the opposite end. The test included: 1) installing the Deita seals and torquing the flange clamps to provide the equivalent sealing force of $960 \mathrm{~N} / \mathrm{cm} ; 2$ ) leak checking the seals; 3) interchanging the seals; 4) torquing the clamps to the equivalent of $1400 \mathrm{~N} / \mathrm{cm}$ sealing force; and 6) leak checking the seals. This test was repeated with four pairs of seals.

No senls leaked on the first installation, and onfy one seal leaked on the second use. This suggested that eves with dramatic changes in sealing surface topography and materials, there is $>85 \%$ probability of the seal being reusable a second time. These test conditions were realistic in the context of actual seal applications in the AGS. 


\section{ELASTOMER SEAL TESTS}

Weight loss and hardness change tests were conducted on three varieties of $V_{i t o n-A}{ }^{\circ}$ and five compounds of Buna- $N^{\circ}$. Outgassing rate measurements were conducted on Vison-A and Buna-N compounds and for comparison purposes, on a sample of polyimide. Our interest in polyimide stems from its use as an electrical insulator in many of the beam components. Besides having good tolerance of radiation, [7] after baking, its ontgassing is less than Viton.8] Peacock provided an excellent review paper of salient publications dealing with vacuum applications of elastomers. [9]

In tests a SLAC elaxtomer gasket materials were exposed to high vacuum for up to three years.[10] with one exception, all compound lots were purchased from the Parter Seal Company. The exception was the material referred to as "Spare ?" material. This material came as a stock of spare O-ring seals provided by the vendor at the time of delivery of over 240 klystron waveguide pumpout valves.[11] The purpose of these tests was to determine if there were irreversible weight and hardness changes in certain elastomers as a consequence of vacuum exposure.

Ninety-five specimen O-ring segments, measuring $5.1 \mathrm{~mm} \phi \times 25 \mathrm{~mm}$ long were individually suspended on wire frames mounted within $\mathrm{Cu}$ pinchoff tubes (see Fig. 4). These, in turn, were welded to a large manifold pumped by a 500 l/sec sputter-ion pump (see Fig 5). Specimens uere pinched off this manifold over a three-year period. The weight and Shore-A hardness of each specimen was measured before and afier extended immersion in high vacuum. Some Viton-A samples were baked in the pinch-off tubes for 24 hours at $\approx 200 \mathrm{C}^{\circ}$. A comparable number of control samples (i.e., $>100$ ), not exposed to vacuum, were also tested for hardness and weight changes throughout the duration of the experiment.

\section{O-RING HARDNESS TEST RESULTS}

The average prevacuum hardness of each sample is given in Table IV. Though hardness increases due to vacuum exposure in all specimens were "statistically significant", fuactionally these changes were of little consequence. The harder the Viton $\mathbf{O}$-ring the less evident the change in bardness as a consequence of prolonged vacuum exposure. The maximum increase in hardness of unbaked Viton, after two years vacumm exposure, was two points. However, both the control and test samples of unbaked Viton became softer by about four Shore-A points as a consequence of prolonged air exposure. There were irreversible changes in hardness of the baked Viton O-rings which amounted to at most +25 points.

No correlation existed between the initial Shore-A hardness of the Buna-N samples and iacreases in hardness as a consequence of vacuum 
exposure. Also, the magnitude of the hardness increase due to vacuum exposure was statistically significant in the case of only one sample type (i.e. +6 points; compound N-532-8), though this was completely reversible There was no correlation between hardness changes and weight loss with the Buns-N materials.

\section{WEIGHT LOSS RESULTS}

The somples exposed to vacuum were weighed $54 \mathrm{~h}, 120 \mathrm{~h}$ and $26000 \mathrm{~h}$ after removal from the pinched-oft capsules. Average differesces of pre-vacuum exposure weights and post-vacuum weights, as a function of air exposure, are given in Table IV for each of these materials. The control samples yielded surprising weight change results (i.e., the far right column). That is, there were real weight increnses in the Viton-A samples and weight decreases in some of the Buna-N samples as a consequence of prolonged air exposure. The population of each control sample lot numbered from 10 to 32 . Therefore, there is confidence in these data.

Weight increases in the Viton control samples obscures interpretation of weight recovery data of both baked and unbaked Viton samples. For example, even after $26000 \mathrm{~h}$ air exposure, the baked samples had not yet returned to their original weights. This is not surprising as one expects plasticizers and unreacted polymers to irreversibly evolve when baking Viton.[12] However, the irreversible weight loss of these samples probably exceeds that indicated because of the tendency of Viton-A, exclusively exposed to air, to increase in weight with time. Data for the baked samples established that irreversible weight loses of the baked Viton samples were inversely related to the initial Shore-A hardness of the test samples.

Using a known, fixed-conductance method, outgassing rates were measured for unbaked Viton-A and Buna-N samples (equivaleat to compounds N-219-7 and 77-545, respectively). A polyimide valve gasket was also tested for comparison purposes. These data are given in Fiz 6. Integrating the outgassing data for the Viton and Buna-N for total weight loss after one year exposure to racuum, weight loss of the Viton sample is $=2.2 \mathrm{mg} / \mathrm{g}$ and weight loss of the Buna- $N$ is $\approx 6.3 \mathrm{mg} / \mathrm{g}$. The Viton outgassing data are in remarkable agreeruent with weight loss data of Table IV. The Buna-N outgassing data were low by 205 from the weight loss data of Table IV. This in part may stem from Blears effects[13] in the measurement apparatus and the known hydrocarbon outgassing of Buna-N. [14,15]

These polymer outgassing data were used to calculate additional beam component pumping which would be required throughout the AGS in order to meet the pressure objectives. These results are reported elsewhere.[16] 


\section{COURSES OF ACTION AND CONCLUSIONS}

Because of the above teat results, the Delta seal was adopted as the standird seal for future we in the AGS. During the 1988 summer shutdown, approxmately $200,216 \mathrm{~mm} \phi$, In coated C-rings and 100 comparably sized "diamoad" seals were replaced with new clamps and Delta seals. Installation problems or inexplicable leats occurred in $-3.0 \%$ of these seals at the time of installation in the AGS. However, after successful installation, there were no Delta seal failures in the following aine months of operation. There were two failures of remaining In costed C-rings in the AGS during this period.

Hardiness changes in elastomers due to vacuum esposure is functionally of no consequence. However, $\mathbf{O}$-ring outgassing dominates in an unbaked system ( $e . g$, the AGS). The nature of accelerator technology requires that portions of the AGS be vented from time to time. Reversible weight changes in elastomers dne to such venting would require that beam component pumping be augmented with high-speed pumps (e.g., cryopumps). One speculates that initial capital investment and maintenance costs associated with augmentation of pumping would far outweigh recurring costs ascociated with the use of large-diameter metal seals. Also, there is some evidence these seals are reusable. Because of these findings, future vacuum seal work is being directed toward evaluation of the Delta seal as a candidate for replacing all of the Lrge-diameter elastomer seals in the AGS. Also work is being done with Delta seals with irregularly shaped major dimensions (e.\&, elliptical shaped seals).

\section{REFERENCES}

Viton $^{\ominus}$ is a registered trade name of E.I. du Pont Memours and Company. Inconel is a registered trade name of the International Nickel Company. ConFlat and Wheeler are registered trade names of Varian Associates. Helicoflex Delta is a registered trade name of the L.C.L. Cefilac Entancheite and patented by CEA Pierrelate (French Atomic Energy Commission).

1. Wheeler, WR, Carkon, M, Trans. 8th Nat. AVS Symp., 2nd Inter. Vac. Cong, 1309 (1961).

2 Wheeler, WR, Trans, 10th Nat. AVS Symp, 159 (1963).

3. Roth A, Vecuum Sealine Techniques (Pergamon Press, London, 1966), p. 308 c.f.

4. Ishimaru, HJ. Vac. Sci. Technol, 15(6), 1853 (1978).

5. The authors are indebted to Drs. Alain Poncet and Hartmut Whal of 
CERN PS and SPS, respectively. Dr. Poncet has successfully used bundreds of "dinmond" seals throughout the CERN PS, where Dr. Whal has made extensive use of the Delta seal, with success in baking, in the CERN SPS. We greatly appreciate their consultations.

6. Roth, A, J. Vac Sci. Technol, $9(1), 14(1972)$.

7. Van de Vorde, M.H, Restat, C, "Selection Guide for Organic Materials For Nuclear Engincering, CERN Report 72-7, 1972.

8. Hait, P.W, Vacuum 17(10), 547(1967).

9. Peacock, R.N., J. Vac. Sci. Technol, 17(1), 330(1980).

10. The authors are indebted to Prof. Dr. J.V. Lebacqz and the staff of the SLAC Klystron Group for their support in this work.

11. Neal, R.B, J. Vac. Sci. Technol. 2 149(1965).

12. de Csernatony, L, Crowley, DJ. Vacuum 17(10), 551(1967); the last of a series of five articles by the authors on this subject.

13. Blears, J, Proc. Roy. Soc London A188, 62(1947).

14. Addis, R.R., et. ㄴll, Trans. 7th Nat. AVS Symp, 39(1960).

15. Sigmond, $T$, et. ㄴ.1, Vacuum 24(1), 231(1964).

16. Welch, KM, et. al., "Refurbisbment of the Vacuum System of the Alternating Gradient Synchrotron," presented at the 11th Inter. Vac Cong., Ko ln (1989). 


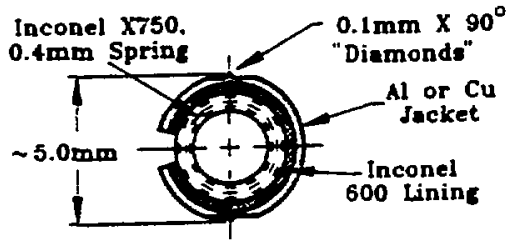

Fic. 1. Approximnte Minor Dimengions of Heliconer Delte Seal used in the AGS.

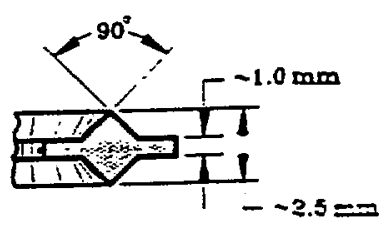

Fie. 2 Minor Dimensions of 날 1100 Aluminum "Diemord Ser's used in the Seal Teat Prograr. 


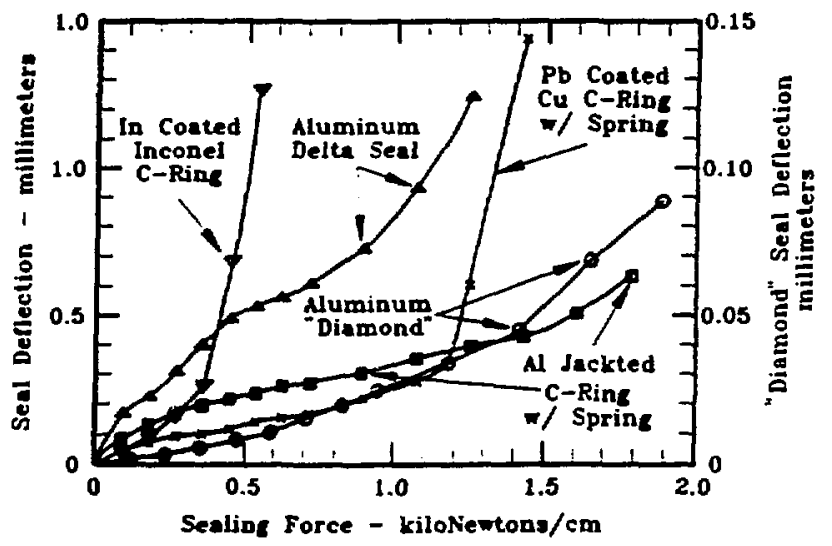

Fic. 3. Seal Denection as a Function of Sealing Force. (Right Scale for "Diamonds"; Left Scale all Other Seals) 
T.I.G. Welded to

T.I.G.

Tacuum Yanifold

Teld

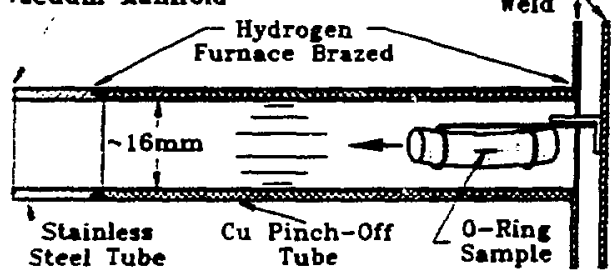

Fig. 4. Copper Pinch-off Assembly Used to House 0 -Ring Test Sample for Extended Vacuum Exposure. 


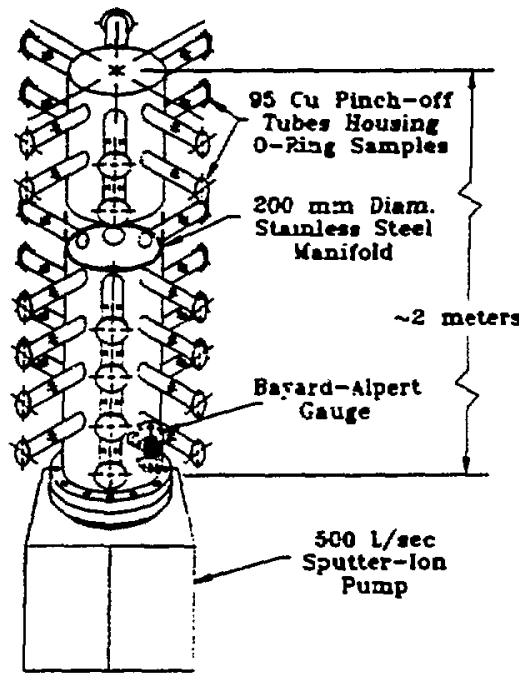

Fig. 5. Apparatus Used to Eraluate the Long Term Effects of Elestomer Exposure to Vacuum. 


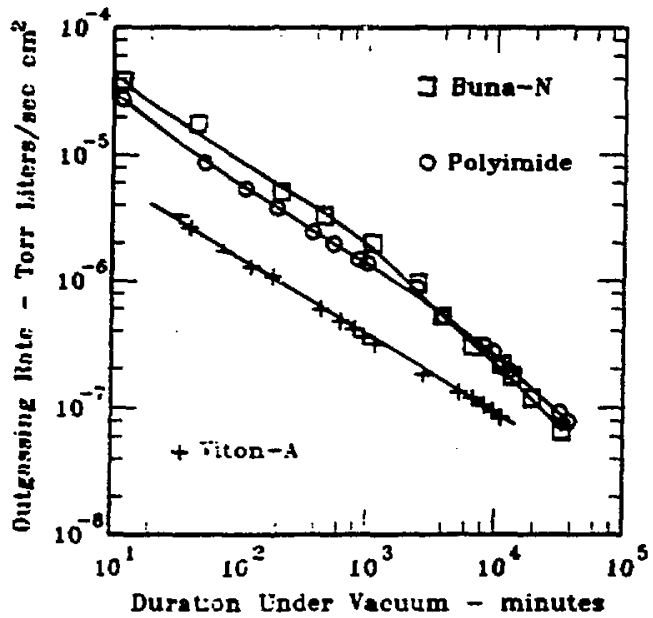

Fig. 6. Outcassing Rate of Three Popular Elastomers as a Function of Time in Vacuum. 


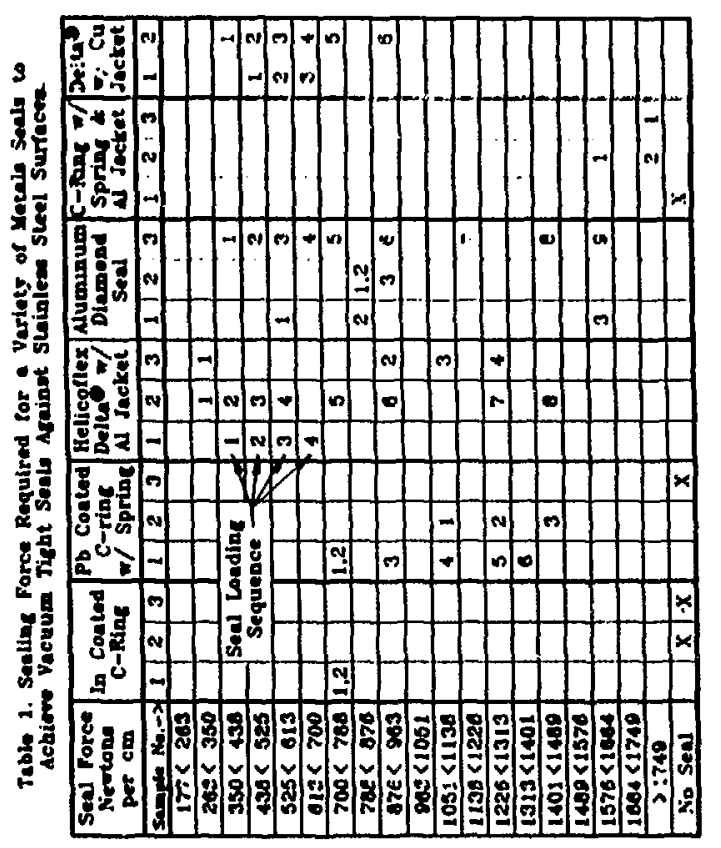




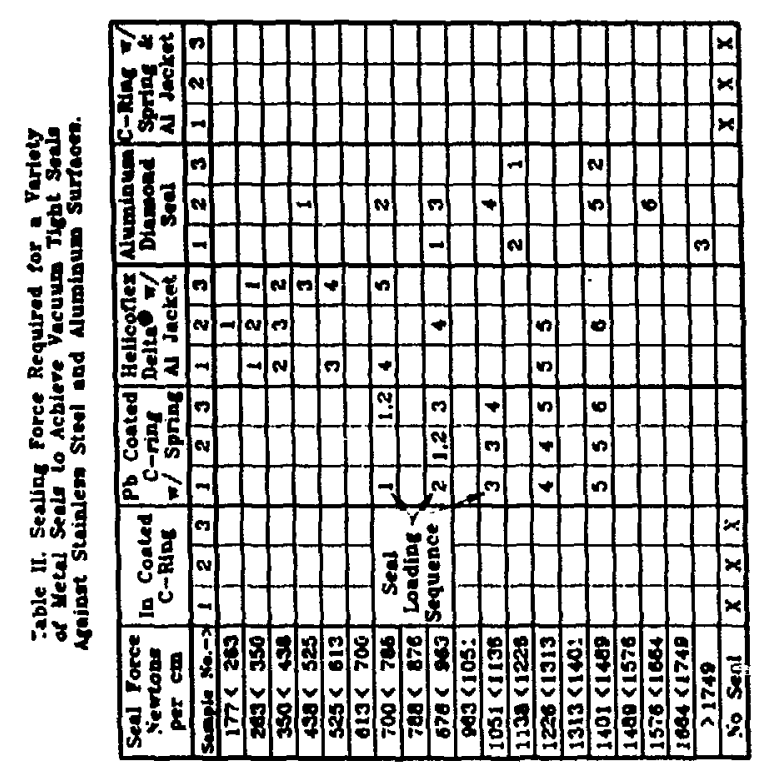


Table m. Sealing Foree Required for Variety

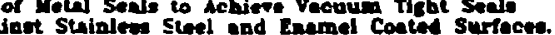

\begin{tabular}{|c|c|c|c|c|c|c|c|c|c|c|c|c|c|}
\hline $\begin{array}{l}\text { Seal Foree } \\
\text { Newions } \\
\text { per cm }\end{array}$ & & $\begin{array}{c}\text { Con } \\
\text { - R4. }\end{array}$ & & $\begin{array}{l}\text { Po Coetes } \\
\text { c-rins } \\
\text { w/ Sprns }\end{array}$ & & & $\begin{array}{c}\mathrm{kez} \\
\mathrm{w} / \\
\mathrm{cet}\end{array}$ & & $\begin{array}{l}\text { nis } \\
\text { Serel }\end{array}$ & & & & \\
\hline $\operatorname{sen} 2 \mathrm{Ne} \rightarrow$ & 1 & 2 & 3 & 1213 & 1 & 2 & 3 & 1 & 2 & 3 & I & 2 & 3 \\
\hline 1776263 & & & & 1 & & & & & & & & & \\
\hline $263<350$ & & & & 1 & & & 1 & & & & & & \\
\hline $350<450$ & & & & 1 & 1 & 1 & 2 & & & & & & \\
\hline $430<525$ & & & & $\vdots$ & & 2 & & & & & & & \\
\hline $525<613$ & & & & $i$ & & & 3 & & & & & & \\
\hline $613<700$ & & ! & 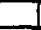 & & 2 & 3 & 4 & & & & & & \\
\hline $700<700$ & & & & - & & & & & & & & & \\
\hline $700<876$ & & $\vdots$ & & 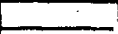 & & & & 1 & & & & & \\
\hline $070<903$ & & & & 1 & 3 & & 5 & & & & & & \\
\hline $983<1051$ & & i & 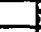 & $\vdots$ & & & & & & & & & \\
\hline $1051<1136$ & & end & & 2 & 4 & 4 & & & & & & & \\
\hline $1130<1226$ & & & & 1 & & & & 2 & i & & & & \\
\hline $1226<1313$ & & & & $!$ & 5 & 5 & 8 & & 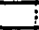 & & & & \\
\hline $1313<1401$ & & & & $\therefore$ & & & & & ; & & & & \\
\hline $1401<1400$ & & & & 3 & $B$ & & & & 1 & & & & \\
\hline $1480<1576$ & & & & 1 & & & & & & & & & \\
\hline $1576<1664$ & & & & $i$ & & & & & & & & $I$ & \\
\hline $1604<1749$ & & & & $I$ & & & & & & & & & \\
\hline$>1749$ & & & & $T$ & & & & & $\bar{z}$ & & & 2 & \\
\hline No Sesl & $x$ & $x$ & $x$ & $x: x$ & & & & & & $\mathbf{x}$ & $x$ & & $x$ \\
\hline
\end{tabular}


Table IY. Summery of Weicht tou of Elantomero Stomming Frose Extanded Exponure to High Vacuum

\begin{tabular}{|c|c|c|c|c|c|c|}
\hline \multirow{2}{*}{\multicolumn{2}{|c|}{$\begin{array}{c}\text { Beked is } \\
\text { Unbalked } \\
\text { o-Ring } \\
\text { Compound }\end{array}$}} & \multirow{2}{*}{$\begin{array}{l}\text { Iorital } \\
\text { Shore-A } \\
\text { Barderes }\end{array}$} & \multicolumn{3}{|c|}{ 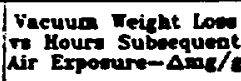 } & \multirow{2}{*}{$\begin{array}{l}\text { Control } \\
\text { Sample } \\
\text { Weight } \\
\text { Gain } \\
\text { smc/s }\end{array}$} \\
\hline & & & $4 \mathrm{~h}$ & $120 \mathrm{~h}$ & 860002 & \\
\hline \multirow{3}{*}{ 章 } & SPARE ? & 10 & 7.3 & - & 3.3 & - \\
\hline & $77-545$ & 80 & 4.1 & $=$ & 1.0 & $=$ \\
\hline & $y-377-0$ & 82 & 6.1 & - & 0.7 & - \\
\hline \multirow{3}{*}{$\begin{array}{l}7 \\
1 \\
\vdots \\
\\
\\
\end{array}$} & SPARE? I & 48 & 2.2 & 1.1 & - & $\overline{-}$ \\
\hline & $77-546$ & 68 & 1.9 & 1.0 & - & 1.3 \\
\hline & $y-377-0$ & 32 & 1.8 & 1.0 & $=$ & 2.0 \\
\hline \multirow{5}{*}{. } & $N-200-5$ & 45 & $\$ 8.1$ & $=$ & +3.1 & -0.3 \\
\hline & $\mathrm{N}-525-6$ & 54 & 14.7 & $=$ & 10.0 & 0.5 \\
\hline & $N-219-7:$ & et & $i 15.0$ & - & 11.6 & 0.8 \\
\hline & $N-532-8 i$ & 70 & 16.7 & $=$ & 11.7 & -0.9 \\
\hline & $\mathrm{N}-5 \mathrm{S2}-\mathrm{9}^{i}$ & 80 & 14.6 & - & 10.0 & -0.6 \\
\hline
\end{tabular}

